Review Article

\title{
Meta-Analysis of Changes in the Number and Proportion of Regulatory T Cells in Patients with Ankylosing Spondylitis
}

\author{
Ming Li $\left(\mathbb{D},{ }^{1}\right.$ Xueping Zhou $\mathbb{D}^{1},{ }^{1}$ Lingling Zhou $\mathbb{D}^{2},{ }^{2}$ Zhichao Yu, ${ }^{1}$ Ling Fu, ${ }^{1}$ and Pei Yang ${ }^{2}$ \\ ${ }^{1}$ The First Clinical Medical College, Nanjing University of Chinese Medicine, Nanjing 210023, China \\ ${ }^{2}$ Jiangsu Provincial Key Laboratory of Pharmacology and Safety Evaluation of Material Medical, School of Pharmacy, \\ Nanjing University of Chinese Medicine, Nanjing 210023, China \\ Correspondence should be addressed to Xueping Zhou; zxp@njucm.edu.cn and Lingling Zhou; zhoulingling@njucm.edu.cn
}

Received 17 September 2019; Accepted 14 January 2020; Published 20 February 2020

Academic Editor: Aziz A. Chentoufi

Copyright (c) $2020 \mathrm{Ming} \mathrm{Li}$ et al. This is an open access article distributed under the Creative Commons Attribution License, which permits unrestricted use, distribution, and reproduction in any medium, provided the original work is properly cited.

\begin{abstract}
Studies on the number and proportion of regulatory T cells (Tregs) in ankylosing spondylitis (AS) patients have been controversial, which has led to a disagreement regarding the role of Tregs in the pathogenesis of AS. To clarify this debate, we conducted a metaanalysis to verify the reported changes in Tregs during AS. We systematically searched the PubMed, Foreign Medical Retrieval System (FMRS), and China National Knowledge Infrastructure (CNKI) web of knowledge databases for eligible articles. A metaanalysis of studies that examined the proportion and number of Tregs among peripheral blood mononuclear cells (PBMCs) and $\mathrm{CD}^{+}$T cells was performed using Stata software. Further, subgroup analysis was performed based on Treg definition markers and disease activity to identify potential sources of heterogeneity. Forty-seven studies involving a total of 4373 participants were included in the meta-analysis. The Treg/PBMC and Treg/CD4 ${ }^{+} \mathrm{T}$ cell ratios were significantly lower in AS patients than those in healthy controls (HCs). A subgroup analysis indicated that patients defined by $\mathrm{CD} 4^{+} \mathrm{CD} 25^{+/ \text {high }}, \mathrm{CD} 4^{+} \mathrm{CD} 25^{+} \mathrm{CD} 127^{\text {low/- }}$, and $\mathrm{CD}^{+} \mathrm{CD} 25^{+} \mathrm{FOXP}^{+}$had much lower Treg/PBMC and Treg/CD4 ${ }^{+} \mathrm{T}$ cell ratios than HCs. Active AS patients also had a substantially lower proportion of Tregs/PBMCs and Treg/CD4 ${ }^{+}$T cells than HCs. The proportion of Tregs among both PBMCs and $\mathrm{CD}^{+}$T cells was significantly decreased in AS patients. Treg definition markers and disease activity may influence the proportion of Tregs measured among the PBMC and $\mathrm{CD} 4^{+}$T cell populations. Further study of the correlation between AS disease activity and the proportion of Tregs in peripheral blood is needed to determine the physiological role of this association. This study implies that loss of Tregs may play a role in the pathogenesis of AS and helps clarify the contradictory Treg results in AS patients. This trial is registered with PROSPERO (CRD42019147064).
\end{abstract}

\section{Introduction}

Ankylosing spondylitis (AS) is a chronic, inflammatory, systemic immune disease, which is characterized by inflammation of the spine and the sacroiliac joints. Traditionally, AS has been implicated in association with human leukocyte antigen B27 (HLA-B27) [1]. However, growing evidence suggests that $\mathrm{T}$ lymphocyte-associated diseases and $\mathrm{CD} 4^{+} \mathrm{T}$ cells and their subsets are involved in AS development [2]. Regulatory $\mathrm{T}$ (Treg) cells are an important component of $\mathrm{CD}^{+} \mathrm{T}$ cells that maintain peripheral tolerance and suppress antigen-specific immune responses by secreting transforming growth factor- $\beta$ (TGF- $\beta$ ), interleukin-10 (IL-10), and IL-4 to inhibit autoimmunity [3-6].
A growing body of evidence suggests that functional defects in Tregs are present in patients with AS and suggests that this may be due to defects in IL-2, decreased phosphorylation of STAT5, decreased expression of fork box P3 $(\mathrm{FOXP} 3)^{+}$, and elevated levels of CpG methylation in the CNS2 region of the FOXP3 gene. Treg cells do not control the proliferation of effector $\mathrm{CD} 4^{+} \mathrm{T}$ cells $[7,8]$, and activation of Tregs has been used to treat AS $[9,10]$.

Despite this evidence, we have less confidence in the possible beneficial effects of therapeutic Tregs in AS patients. Whether and how Tregs participate in the pathogenesis of AS has not been fully elucidated, and data on Tregs in AS patients has been controversial. At present, studies on Tregs in ankylosing spondylitis focus on the number and function 
of Tregs in patients with ankylosing spondylitis, but the results were not consistent; a reduction [11-13], elevation $[8,14,15]$, and no significant change $[16,17]$ in the number of Tregs in AS patients have all been reported. The possible reasons for these discrepant results are mainly due to the ambiguity of Treg surface-specific markers or the degree of disease activity at the time of patient detection. In addition, it is necessary to specifically indicate that the number of Tregs is inconsistent. For example, some studies use Treg/PBMC (\%), while some use Treg/CD4 ${ }^{+} \mathrm{T}$ cells (\%)-the former focuses on describing changes in the amount of Treg in the peripheral blood, while the latter focuses more on the change in a ratio relative to all $\mathrm{T}$ cells.

Given that the quantitative and qualitative changes in Tregs in AS are still unclear, Tregs have been suggested to play an important role in the pathogenesis of AS, and Tregbased immunotherapies show promising potency, here we did a metadata analysis to investigate the proportion of Tregs in PBMC and $\mathrm{CD}^{+} \mathrm{T}$ cells in AS patients. Understanding changes in the number of Tregs during AS will help us understand the role of Tregs in the pathogenesis of AS in more detail.

\section{Materials and Methods}

2.1. Data Sources and Searches. Three Chinese language databases and five English language databases were widely searched for all relevant results until April 10, 2019. The Chinese language databases were China National Knowledge Infrastructure (CNKI), VIP Database (VIP), and Wanfang Data. The five English language databases were PubMed, ScienceDirect, Foreign Medical Retrieval System (FMRS), EMBASE, and Cochrane Library. We also supplemented the search results using Google Scholar. The literature search strategy used the following terms: English ("regulatory $\mathrm{T}$ cells" OR "Treg” OR " $\mathrm{CD} 4^{+} \mathrm{CD} 25^{+} \mathrm{T}$ cell” OR “CD $4^{+} \mathrm{CD} 25^{\text {high }} \mathrm{T}$ cell” $\mathrm{OR}$ "CD25 $5^{+} \mathrm{CD} 127^{\text {low }} \mathrm{T}$ cell” $\mathrm{OR}$ “CD $4^{+} \mathrm{CD} 25^{+} \mathrm{FOXP}^{+}$T cell”) AND ("Ankylosing spondylitis" OR “AS”) and related Chinese ("qiang zhi xing ji zhu yan" OR "qiang zhi”) AND ("tiao jie xing T xi bao" OR "Treg" OR " $\mathrm{CD} 4^{+} \mathrm{CD} 25^{+} \mathrm{T}$ cell" $\mathrm{OR}$ " $\mathrm{CD} 4^{+} \mathrm{CD} 25^{\text {high }} \mathrm{T}$ cell" $\mathrm{OR}$ “CD25 ${ }^{+} \mathrm{CD} 127^{\text {low }} \mathrm{T}$ cell” OR “ $\mathrm{CD} 4{ }^{+} \mathrm{CD} 25^{+} \mathrm{FOXP} 3^{+} \mathrm{T}$ cell”).

\subsection{Study Selection}

2.2.1. Inclusion Criteria. The following criteria were used to determine if a search result was included in the analysis: (a) original research (not a commentary), (b) human research, (c) the terms "ankylosing spondylitis" and "regulatory T" (or "Treg") included in the title or abstract, (d) studies that report the proportion of Tregs in $\mathrm{CD}^{+} \mathrm{T}$ cells or peripheral blood of AS patients, and (e) studies that can be found on the Internet; the manuscript is linked from the search site to the full text of the manuscript (PDF or website). At the same time, we validated that all AS patients in the selected study were diagnosed according to the 1984 AS New York revised standard [18].
2.2.2. Exclusion Criteria. The following criteria were used to exclude a search result from the analysis: (a) no raw data on the mean and standard deviation (SD) of the ratio of Tregs in $\mathrm{CD}^{+}$T cells in $\mathrm{PB}$ of AS patients or control subjects and (b) no original information on the number of AS patients or control subjects included in the study. Also, the duplicates between PubMed and Google Scholar search were included only once in the analysis.

2.3. Data Extraction. Two independent researchers (Ming Li and Zhichao $\mathrm{Yu}$ ) extracted data from qualified articles according to the set criteria, cross-checked the data, and, in the case of controversial questions, asked the third commentator to join the discussion to resolve the dispute. The data extraction includes the first author's name, publication year, the number of patients and healthy people, the definition of Treg, Treg frequency, diagnostic criteria, and criteria for determining the active period of AS. The NOS was used to assess the quality of the included studies.

2.4. Validity and Quality Assessment. According to the rules and scoring criteria of the Newcastle-Ottawa Quality Assessment Scale (NOS) observational quality assessment tool [19], two authors (ML and ZCY) independently assessed the methodological quality of the included studies. A third author (ZXP) was available to discuss disagreements.

2.5. Data Analysis. We used Stata12.0 software (Version 12.0; STATA Corporation, College Station, TX, USA) for the statistical analysis. Heterogeneity was assessed using the $I^{2}$ statistic. When the heterogeneity was high (i.e., $p<0.05$, $I^{2}>50 \%$ ), then a random-effects model was adopted and the source of heterogeneity was analyzed. Publication bias was assessed by the Egger and Begg method. Sensitivity analyses were conducted to test the robustness of the original results.

\section{Results}

3.1. Literature Search Results. According to the above search method, 1523 articles were retrieved. A flow chart of the screening process for the articles is shown in Figure 1. First, 86 duplicate articles were excluded. Then, A total of 1112 articles were excluded by screening the titles and abstracts. By reading the full text carefully, articles without original data, controls, or human experiments were excluded, and 47 studies were finally included in the analysis.

3.2. Study Characteristics. All of the features included in the study are listed in Tables 1 and 2. This meta-analysis included 2,514 AS patients and 1,859 healthy controls from 47 eligible studies. These studies include one active AS study. Among the 47 included studies, 37 were used to analyze Tregs/PBMCs in AS patients and healthy controls (HCs), 14 were used to analyze Tregs/CD4 ${ }^{+}$T cells in AS patients and HCs, and 4 were used to analyze both Tregs/PBMC and Tregs/CD4 ${ }^{+} \mathrm{T}$ cell ratios in AS patients and HCs. Criteria for evaluating disease activity and diagnostic criteria were also collected. Based on the quality 


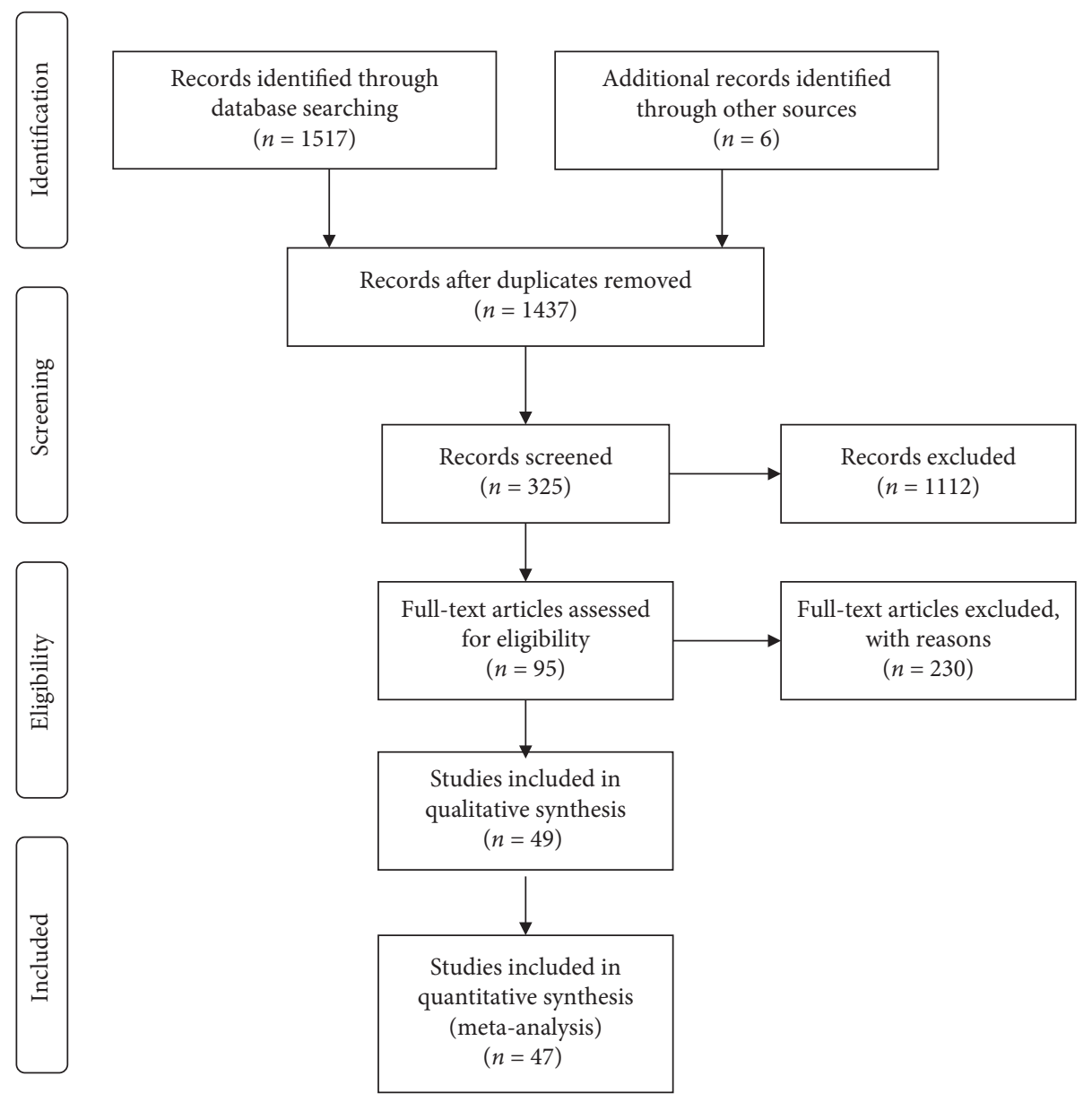

Figure 1: Flow chart of studies included in the meta-analysis.

evaluation criteria of the case-control study based on the NOS, two $[31,49]$ of the 47 studied scored 4 points, 24 [13-16, $20,21,23-26,30,32,36,37,39,42,44-46,51,54,55,57,59]$ scored 5 points, and $16[12,22, \quad 27-29, \quad 33-35$, $38,40,41,43,47,50,52,53,56,58,60]$ scored 6 points, one [45] of the 7 points. The overall quality of the study is moderate.

3.3. Proportion of Tregs in the PB of AS Patients. First, we compared the proportion of Tregs among PBMCs in the peripheral blood of AS patients and HCs. We initially compared the proportion of Tregs in AS patients and healthy controls regardless of the Treg definition used. In the overall analysis, high heterogeneity $\left(I^{2}=92.50, p \leq 0.001\right)$ was observed between the studies, and a random-effects model was used in the meta-analysis. We discovered that the percentage of Tregs in AS was significantly lower than those in controls $[-0.071,(-0.79,-0.64), p \leq 0.001]$ (Figure 2).

We hypothesized that the primary reason for the unexpected results might be that the definitions of Tregs were inconsistent. Thus, we performed a subgroup analysis based on Treg definitions to explore the potential sources of heterogeneity (Table 3). First, we analyzed studies that identified Tregs only as "CD25-positive." Pooled analysis of all 14 trials revealed a significant decrease in the proportion of Tregs in AS patients compared to controls [ -0.369 , $(-0.493,-0.249), p \leq 0.001]$ with statistically significant interstudy heterogeneity $\left(I^{2}=91.6 \%, p \leq 0.001\right)$. In detail, we found significant differences in the proportion of Tregs between AS patients and healthy controls when Tregs were defined as "CD4 ${ }^{+} \mathrm{CD} 25^{+}$” cells $[-0.395,(-0.578,-0.212)$, $p \leq 0.001]$ and as "CD $4^{+} \mathrm{CD} 25^{\text {high" }}$ cells $[-0.347,(-0.515$, $-0.178), p \leq 0.001]$.

Second, the other 14 groups that used "CD127 $7^{\text {low/-” }}$ to define Tregs showed that such cell numbers decreased in AS patients $[-0.912,(-1.038,-0.786), p \leq 0.001]$ with statistical heterogeneity $\left(I^{2}=87.3 \%, p \leq 0.001\right)$. More specifically, we found significant differences in the proportion of Tregs between AS patients and healthy controls when Tregs were defined as "CD $4^{+} \mathrm{CD} 25^{+} \mathrm{CD} 127^{\text {low/-" }}$ cells $[-0.855,(-1.065$, $-0.646), p \leq 0.001]$ and as "CD $4{ }^{+} \mathrm{CD} 25^{\text {high }} \mathrm{CD} 127^{\text {low/-” }}$ cells $[-0.944,(-1.101,-0.787), p \leq 0.001]$.

Finally, we analyzed 13 groups in which Tregs were defined as "FOXP ${ }^{+}$" cells. Pooled analysis of all 13 trials showed that such cell numbers decreased in AS patients $[-0.666,(-0.820,-0.512), p \leq 0.001]$ with statistical heterogeneity $\left(I^{2}=94.5 \%, p \leq 0.001\right)$. More specifically, twelve studies used "CD $4{ }^{+} \mathrm{CD} 25^{+} \mathrm{FOXP} 3$ " to define Tregs, and pooled analysis showed that such cell numbers decreased in AS patients [-0.835, $(-0.995,-0.674), p \leq 0.001]$ with 


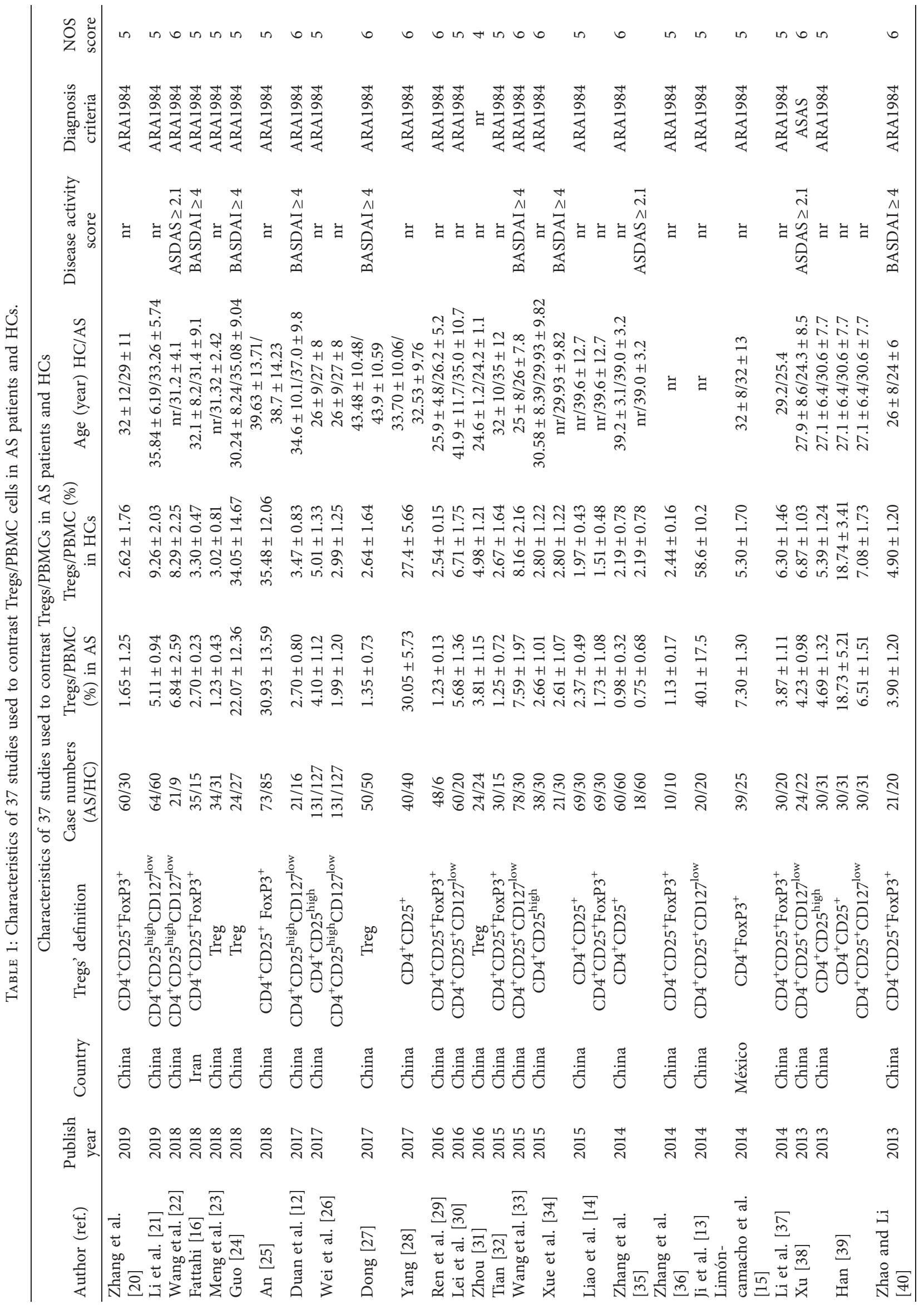




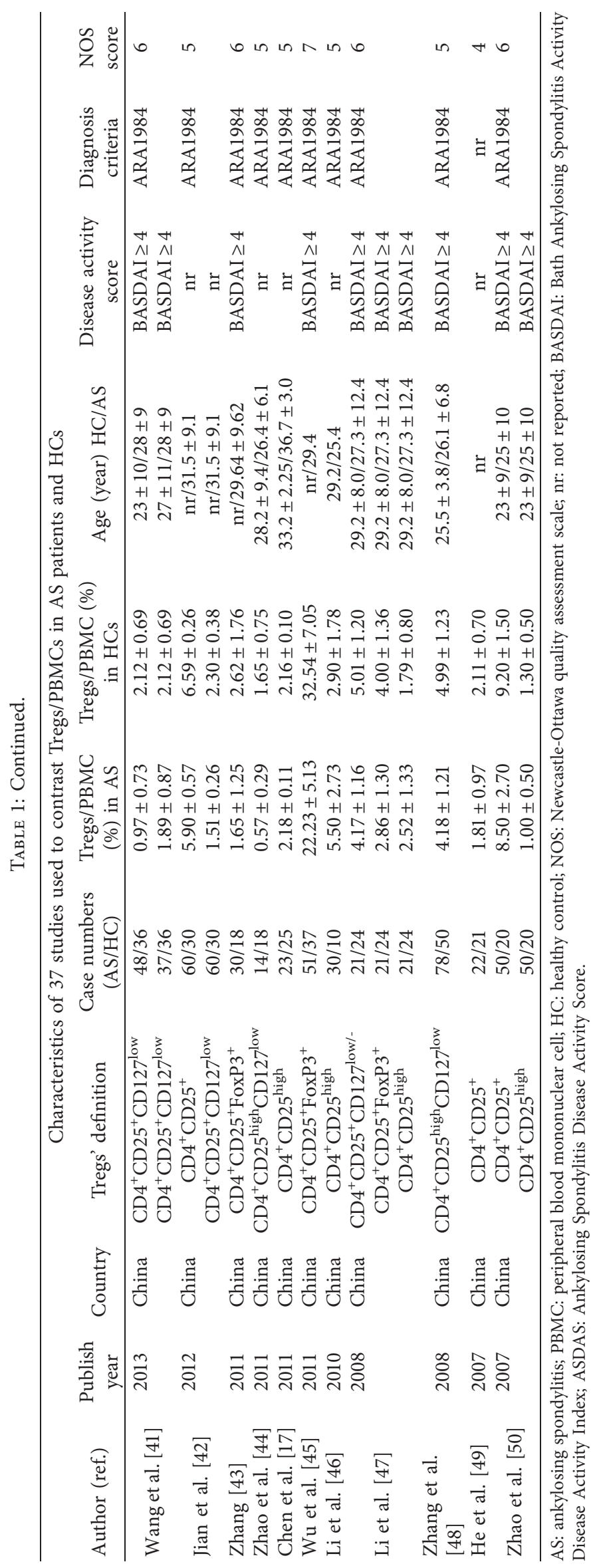




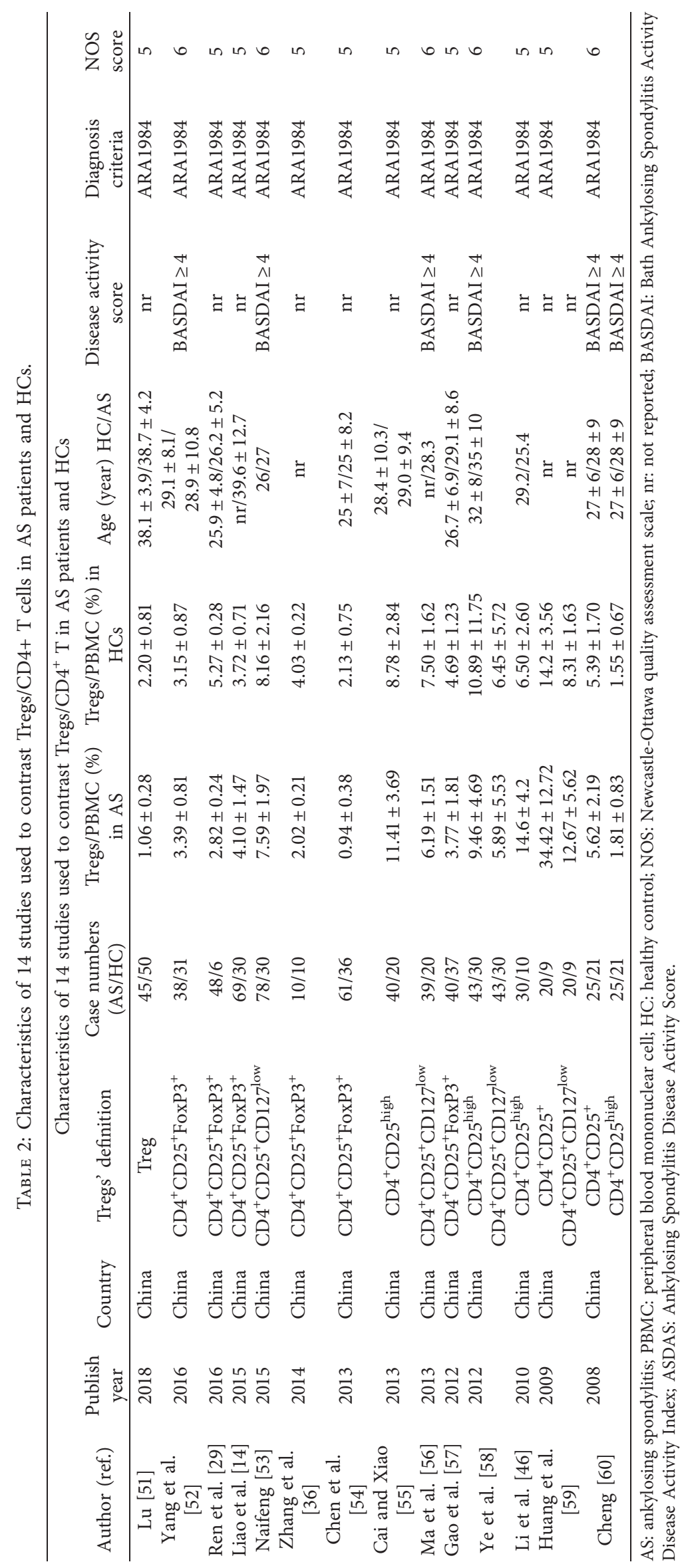




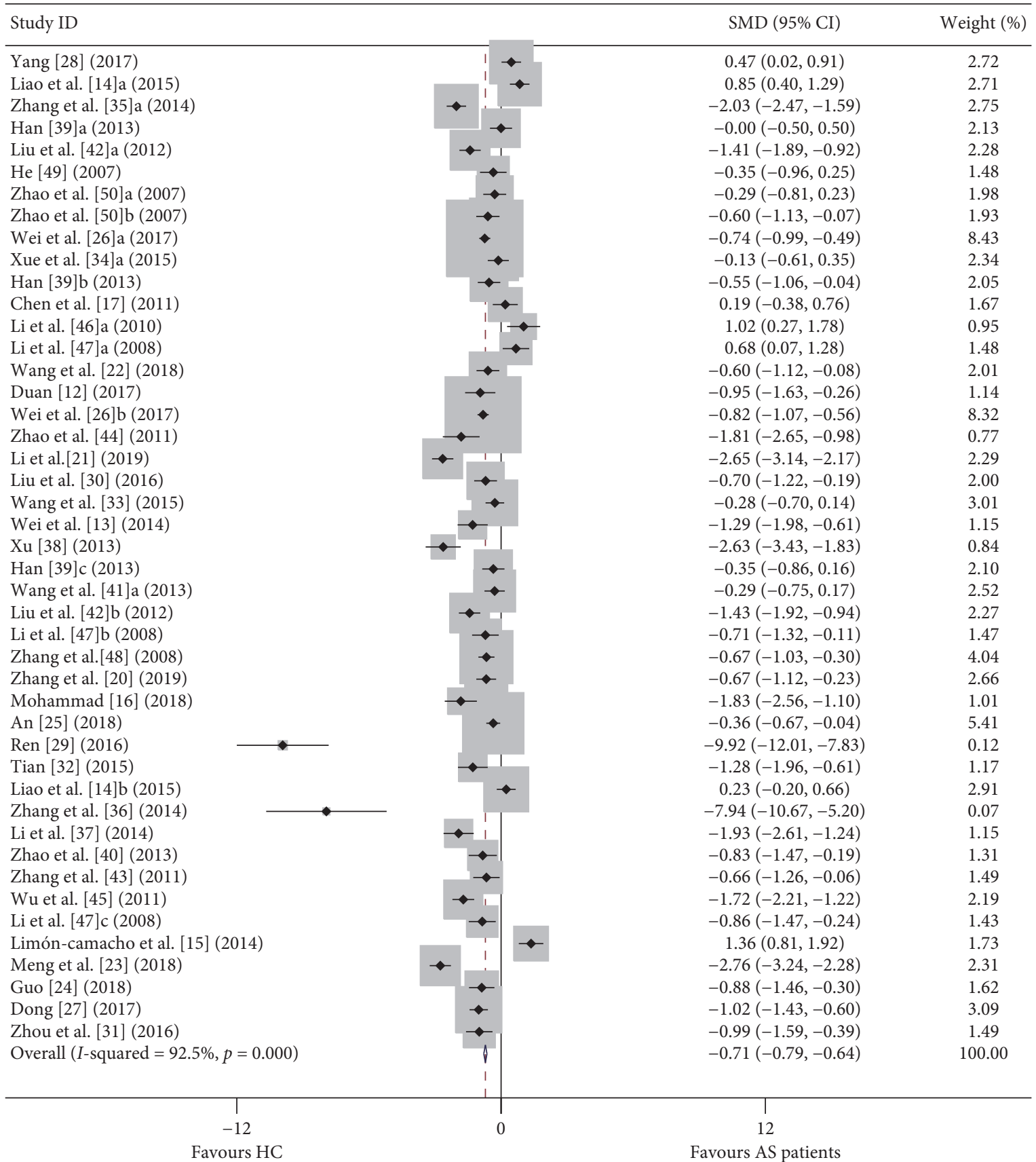

FIgURE 2: Forest plot of the percentage changes of Tregs in AS patients compared with HCs. SMD: standardized mean difference; CI: confidence interval; AS: ankylosing spondylitis; HC: healthy control; PBMC: peripheral blood mononuclear cell.

statistical heterogeneity $\left(I^{2}=93.2 \%, p \leq 0.001\right)$. One study used "CD3 ${ }^{+} \mathrm{CD} 4{ }^{+} \mathrm{FOXP} 3$ " " to define Tregs, so no further analysis was conducted on this study.

To explore the correlation between AS disease activity and the number of Tregs in peripheral blood, we further contrasted the results for active AS patients and HCs (Table 4). We have included a total of 23 studies and found a significant reduction in the proportion of Tregs in patients with active compared to inactive disease $[-0.878,(-0.993$, $-0.762), p \leq 0.001]$, regardless of the Tregs definitions used.
The $I^{2}$ values also showed very high heterogeneity $\left(I^{2}=88.0 \%, p \leq 0.001\right)$. Thus, we performed a subgroup analysis based on the Treg definitions to explore the potential sources of heterogeneity in active AS patients. In detail, we found significant differences in the proportion of Tregs between active AS patients and healthy controls when Tregs were defined as "CD25-positive" cells $[-0.493,(-0.720$, $-0.267), p \leq 0.001]$ with statistical heterogeneity $\left(I^{2}=88.7 \%\right.$, $p \leq 0.001)$. More specifically, Tregs were identified as “CD $4{ }^{+} \mathrm{CD} 25^{+”}$ cells $[-0.884,(-1.201,-0.567), p \leq 0.001]$, 
TABLE 3: Subgroup analysis based on Treg definitions.

\begin{tabular}{|c|c|c|c|c|c|c|c|c|c|c|c|c|}
\hline \multirow[b]{2}{*}{ Tregs definition } & \multicolumn{6}{|c|}{ Analysis of Tregs/PBMCs } & \multicolumn{6}{|c|}{ Analysis of Tregs/CD $4^{+} \mathrm{T}$ cells } \\
\hline & $\begin{array}{c}\text { Number } \\
\text { of studies } \\
(n)\end{array}$ & SMD & $95 \% \mathrm{CI}$ & $P^{\mathrm{a}}$ & $\begin{array}{c}I^{2} \\
(\%)\end{array}$ & $P^{\mathrm{b}}$ & $\begin{array}{c}\text { Number } \\
\text { of studies } \\
(n)\end{array}$ & SMD & $95 \% \mathrm{CI}$ & $P^{\mathrm{a}}$ & $\begin{array}{c}I^{2} \\
(\%)\end{array}$ & $P^{\mathrm{b}}$ \\
\hline $\mathrm{CD} 4^{+} \mathrm{CD} 25^{\text {positive }}$ & 14 & -0.369 & $-0.493,-0.2$ & $<0.001$ & 91.6 & $<0$. & 6 & 0.495 & 0.247 & $<0.001$ & 84.5 & $<0.001$ \\
\hline $\mathrm{CD} 4^{+} \mathrm{CD} 25^{+}$ & 7 & -0.395 & $-0.578,-0.212$ & $<0.001$ & 94.8 & $<0.001$ & 2 & 0.606 & 0.113 & 0.016 & 89.8 & 0.002 \\
\hline $\mathrm{CD} 4^{+} \mathrm{CD} 25^{\text {high }}$ & 7 & -0.347 & $-0.515,-0.178$ & $<0.001$ & 84.6 & $<0.001$ & 4 & 0.457 & $0.171,0.744$ & 0.002 & 86.5 & $<0.001$ \\
\hline $\begin{array}{l}\mathrm{CD} 4^{+} \mathrm{CD} 25^{\text {positive }} \\
\mathrm{CD} 127^{\text {low/- }}\end{array}$ & 14 & -0.912 & $-1.038,-0.786$ & $<0.001$ & 87.3 & $<0.001$ & - & - & - & - & - & - \\
\hline $\begin{array}{l}\mathrm{CD} 4^{+} \mathrm{CD} 25^{+} \\
\mathrm{CD} 127^{\text {low } /-}\end{array}$ & 4 & -0.855 & $-1.065,-0.646$ & $<0.001$ & 51.2 & 0.105 & 4 & -0.228 & $-0.488,0.032$ & 0.085 & 75.5 & 0.006 \\
\hline $\begin{array}{l}\mathrm{CD} 4^{+} \mathrm{CD} 25^{\text {high }} \\
\mathrm{CD} 127^{\text {low } /-}\end{array}$ & 10 & -0.944 & $-1.101,-0.787$ & $<0.001$ & 90.6 & $<0.001$ & - & - & - & - & - & - \\
\hline $\mathrm{CD}^{+} \mathrm{CD}^{+} 5^{+} \mathrm{FoxP}^{+}$ & 12 & -0.835 & $-0.995,-0.674$ & $<0.001$ & 93.2 & $<0.001$ & 5 & -0.494 & $-0.727,-0.261$ & $<0.001$ & 95.8 & $<0.001$ \\
\hline $\mathrm{CD}^{+}{ }^{+} \mathrm{CD} 4^{+} \mathrm{FoxP}^{+}$ & 1 & 1.363 & $0.806,-1.919$ & $<0.001$ & - & - & - & - & - & - & - & - \\
\hline Treg & 4 & -1.460 & $-1.711,-1.208$ & $<0.001$ & 92.2 & $<0.001$ & 1 & -0.229 & $-0.365,-0.093$ & $<0.001$ & - & - \\
\hline
\end{tabular}

but no significant difference was apparent when Tregs were defined as "CD $4{ }^{+} \mathrm{CD} 25^{\text {high" }}$ cells $[-0.085,(-0.409,0.238)$, $p \leq 0.606]$.

When Tregs were defined as "CD127 $7^{\text {low/-” cells, pooled }}$ analysis of all 36 trials revealed a significant difference $[-0.889,(-1.086,-0.692), p \leq 0.001]$ with statistical heterogeneity $\left(I^{2}=83.0 \%, p \leq 0.001\right)$. More specifically, Tregs were identified as "CD $4^{+} \mathrm{CD} 25^{+} \mathrm{CD} 127^{\text {low/-” }}$ cells $[-0.937$, $(-1.161,-0.714), \quad p \leq 0.001]$ and as " $\mathrm{CD} 4{ }^{+} \mathrm{CD} 25^{\text {high }}$ CD127 ${ }^{\text {low/-» }}$ cells $[-0.724,(-1.138,-0.311), p \leq 0.001]$. Finally, the other eight groups that used "CD $4^{+} \mathrm{CD} 25^{+} \mathrm{FOXP} 3^{+}$" to define Tregs showed that such cell numbers decreased in active AS patients $[-1.180,(-1.397$, $-0.962), p \leq 0.001]$ with statistical heterogeneity $\left(I^{2}=91.8 \%\right.$, $p \leq 0.001)$.

We also consider that the evaluation criteria of the AS active period are different, which may be another source of heterogeneity. So, we conducted a subgroup analysis based on the different evaluation criteria of the AS activity period. We found significant differences in the proportion of Tregs between active AS patients and healthy controls when the evaluation criteria of AS active period were based on the Bath Ankylosing Spondylitis Activity Index (BASDAI) $[-0.793,(-0.918,-0.667), p \leq 0.001]$ and the Ankylosing Spondylitis Disease Activity Score (ASDAS) [-1.487, $(-1.824,-1.151), p \leq 0.001]$.

3.4. Proportion of Tregs in the CD $4^{+} T$ Cells of AS Patients. In this meta-analysis, among the 47 included studies, 14 were used to analyze Tregs/CD $4^{+} \mathrm{T}$ cells in AS patients and HCs. We initially compared the proportion of Tregs in AS patients and healthy controls regardless of the Treg definition used. In the overall analysis, high heterogeneity $\left(I^{2}=93.20, p \leq 0.001\right)$ was observed between the studies, and a random-effects model was used in the meta-analysis. We discovered that the percentages of Tregs in AS were significantly lower than those in controls $(-0.229,(-0.365$, $-0.093), p \leq 0.001$ ) (Figure 3 ). We also performed a subgroup analysis based on the Treg definitions to explore the potential sources of heterogeneity (Table 4).
Tregs were identified as " $\mathrm{CD} 4{ }^{+} \mathrm{CD} 25^{+} \mathrm{CD} 127^{\text {low/-” }}$ cells $(-0.228,(-0.488,0.032), p=0.006)$ with statistical heterogeneity $\left(I^{2}=75.5 \%, p=0.163\right)$ and Tregs were identified as “CD $4{ }^{+} \mathrm{CD} 25^{+} \mathrm{FOXP}^{+}$” cells $(-0.494,(-0.727,-0.261)$, $p \leq 0.001)$ with statistical heterogeneity $\left(I^{2}=95.8 \%\right.$, $p \leq 0.001)$.

To explore the correlation between AS disease activity and the number of Tregs in peripheral blood, we further contrasted results for active AS patients and HCs (Table 4). Similarly, we also explored the correlation between AS disease activity and Treg ratios in $\mathrm{CD} 4^{+} \mathrm{T}$ cells. We found significant differences in the proportion of Tregs between active AS patients and healthy controls when Tregs were

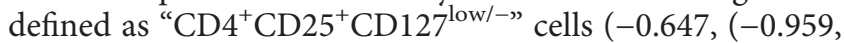
$-0.336), p \leq 0.001)$ with statistical heterogeneity $\left(I^{2}=44.9 \%\right.$, $p=0.163)$, but no significant difference was apparent when Tregs were defined as "CD $4{ }^{+} \mathrm{CD} 25^{\text {positive" }}$ cells $(0.132$, $(-0.195,0.459), p=0.428)$. There was only one study that defined Tregs as "CD $4{ }^{+} \mathrm{CD} 25^{+} \mathrm{FOXP} 3$ ", so no further analysis was conducted for this study. Both ASDAS and BASDAI can be used as a measure of AS disease activity. So, we also conducted a subgroup analysis based on the different evaluation criteria of the AS activity period (Table 4). We found significant differences in the proportion of Tregs between active AS patients and healthy controls when the evaluation criteria of AS active period were based on "BASDAI" $(-1.512,(-2.488,-0.535), p=0.002)$ and as "ASDAS" cells $(-1.074,(-1.830,-0.318), p=0.005)$ and as “FOXP3 " cells $(-1.074,(-1.830,-0.318), p=0.005)$.

3.5. Publication Bias. A meta-analysis of 37 studies on the changes in the number of Tregs in peripheral blood and 14 studies on the changes in the proportion of Tregs in $\mathrm{CD} 4^{+}$ T cells in patients with AS showed no obvious publication bias by Egger's test $((t=-1.91, p=0.063)$ and $(t=0.17$, $p=0.870)$, respectively) (Figure 4$)$.

3.6. Sensitivity Analysis. We conducted a sensitivity analysis to identify possible sources of heterogeneity in studies that determined the proportion of Tregs/PBMC and Tregs/CD $4^{+}$ 


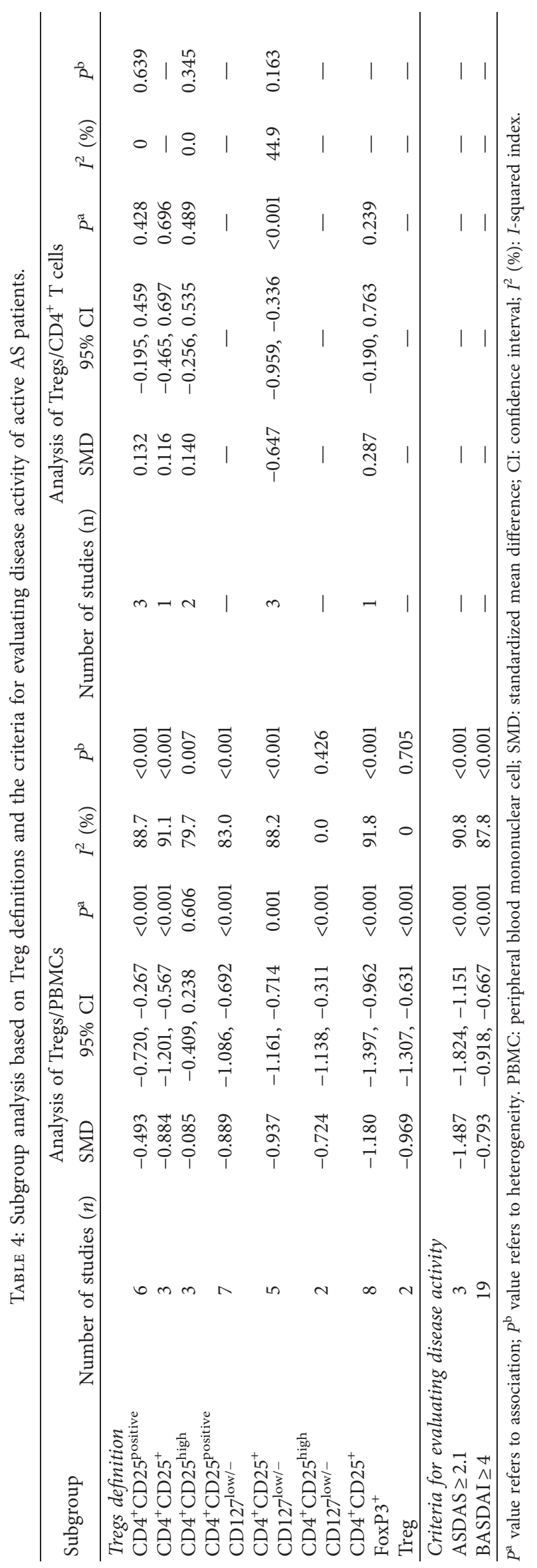




\begin{tabular}{|c|c|c|c|}
\hline \multicolumn{2}{|l|}{ Study ID } & \multirow{2}{*}{$\frac{\operatorname{SMD}(95 \% \mathrm{CI})}{0.77(0.21,1.32)}$} & \multirow{2}{*}{$\frac{\text { Weight }(\%)}{6.03}$} \\
\hline Cai et al. [55] (2013) & $\rightarrow$ & & \\
\hline Ye et al. [58]a (2012) & $\rightarrow$ & $-0.17(-0.64,0.30)$ & 8.50 \\
\hline Li et al. [46]b (2010) & $1 \rightarrow$ & $2.09(1.23,2.94)$ & 2.53 \\
\hline Cheng et al. [60]b (2007) & $\rightarrow$ & $0.34(-0.23,0.92)$ & 5.57 \\
\hline Huang et al. [59]a (2009) & $\longrightarrow$ & $1.86(0.93,2.80)$ & 2.14 \\
\hline Cheng et al. [60]a (2007) & $\rightarrow$ & $0.12(-0.46,0.70)$ & 5.50 \\
\hline Zhong et al. [53] (2013) & $\leftarrow$ & $-0.28(-0.70,0.14)$ & 10.38 \\
\hline Ma et al. [56] (2013) & $\rightarrow$ & $-0.85(-1.41,-0.29)$ & 5.89 \\
\hline Ye et al. [58]b (2012) & $\rightarrow$ & $-0.10(-0.57,0.37)$ & 8.52 \\
\hline Huang et al. [59]b (2009) & $1+$ & $0.91(0.09,1.73)$ & 2.74 \\
\hline Yang et al. [52] (2016) & $\rightarrow$ & $0.29(-0.19,0.76)$ & 8.16 \\
\hline Liao et al. [14] (2015) & $\leftrightarrow$ & $0.29(-0.14,0.73)$ & 10.00 \\
\hline Zhang et al. [36] (2014) & 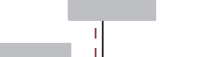 & $-9.35(-12.52,-6.17)$ & 0.18 \\
\hline Chen et al. [54] (2013) & $\rightarrow \quad 1$ & $-2.18(-2.69,-1.66)$ & 6.98 \\
\hline Gao et al. [57] (2012) & $\bullet$ & $-0.59(-1.05,-0.13)$ & 8.88 \\
\hline Lu et al. [51] (2018) & $\rightarrow \quad i$ & $-1.84(-2.32,-1.36)$ & 7.98 \\
\hline Overall $(I$-squared $=93.2 \%, p=0.000)$ & 4 & $-0.23(-0.37,-0.09)$ & 100.00 \\
\hline $\begin{array}{c} \\
-12.5 \\
\text { Favours HC }\end{array}$ & $\begin{array}{c}4 \\
0\end{array}$ & $\begin{array}{c}1 \\
12.5 \\
\text { Favours AS patients }\end{array}$ & \\
\hline
\end{tabular}

FIgURe 3: Forest plots generated by meta-analysis for the findings of Tregs/CD4 ${ }^{+} \mathrm{T}$ cells in AS patients and HCs. SMD: standardized mean difference; CI: confidence interval; AS: ankylosing spondylitis; HC: healthy control; PBMC: peripheral blood mononuclear cell.

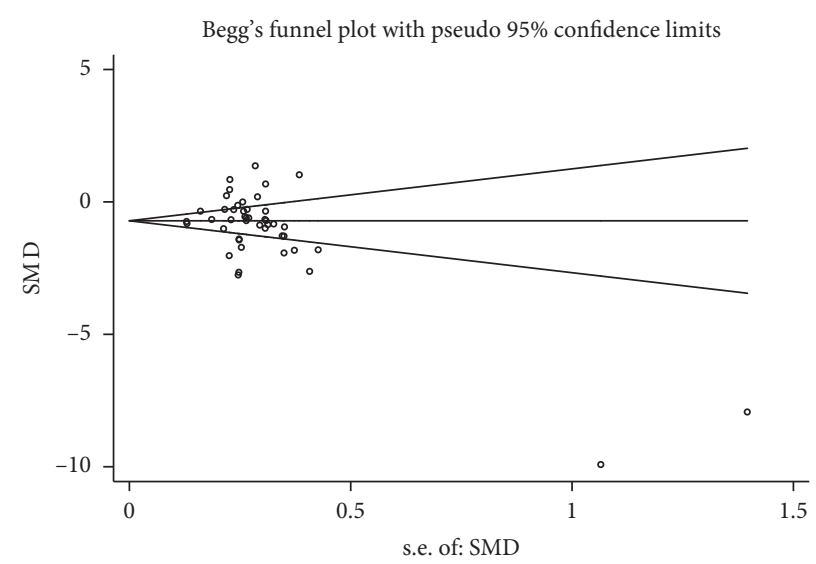

(a)

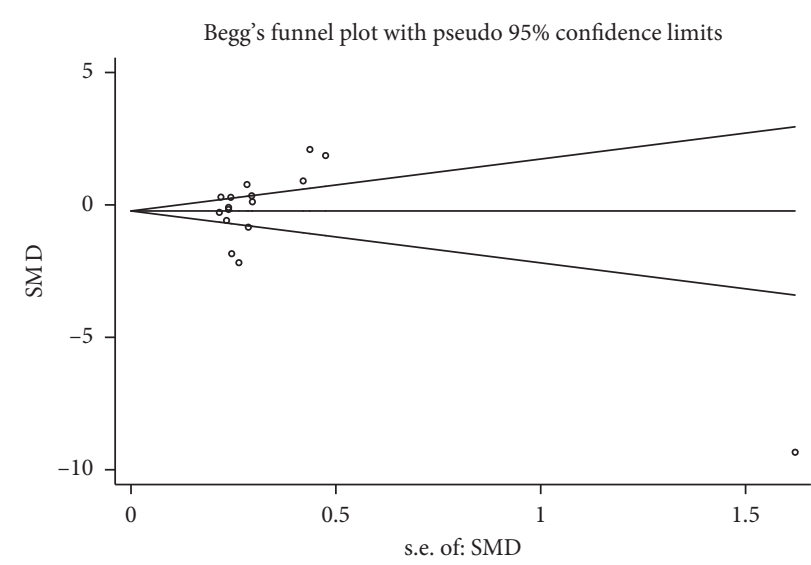

(b)

FIgURE 4: Funnel plot. For interpretation of any publication bias among studies, visual inspection of the generated funnel plot was employed to evaluate symmetry. The funnel plot appears symmetrical.

T cells. Single studies were successively eliminated without any substantial change in the results. This indicated that the results of the meta-analysis were relatively stable (Figure 5).

\section{Discussion}

Regulatory T cells suppress effector cells through a number of secreted and surface-expressed proteins and play an indispensable role in maintaining immune homeostasis and preventing autoimmunity induced by excessive, misleading, or unnecessary immune activation $[61,62]$. It is now widely accepted that Treg cells mediate immune tolerance through the immunosuppressive cytokines TGF- $\beta$, IL-10, and IL-35. Also, because of the high expression of CD25 in Treg cells, Treg cells are able to clear IL-2, which is a crucial feature [63]. Traditionally, functional defects in Treg cells are 


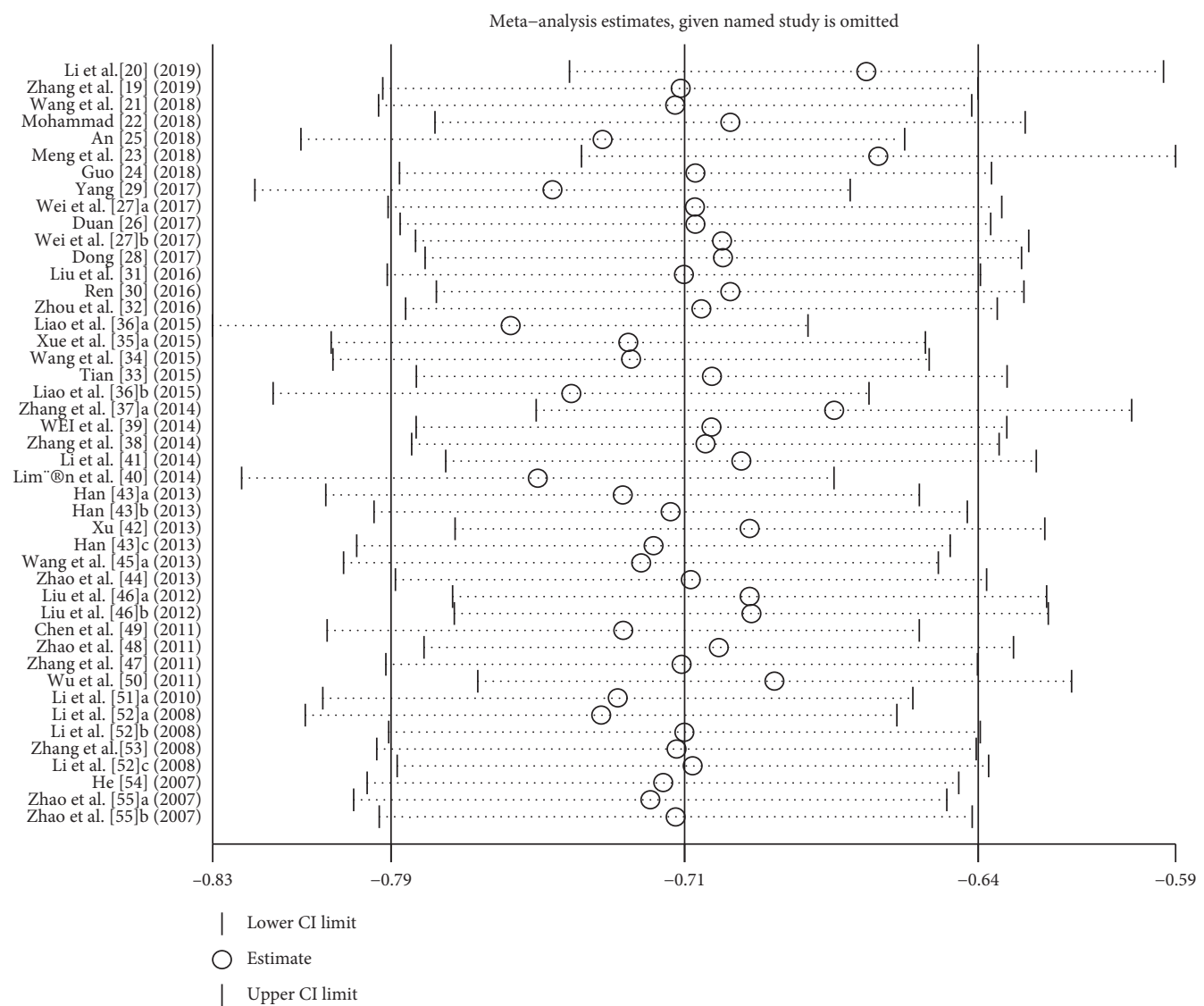

(a)

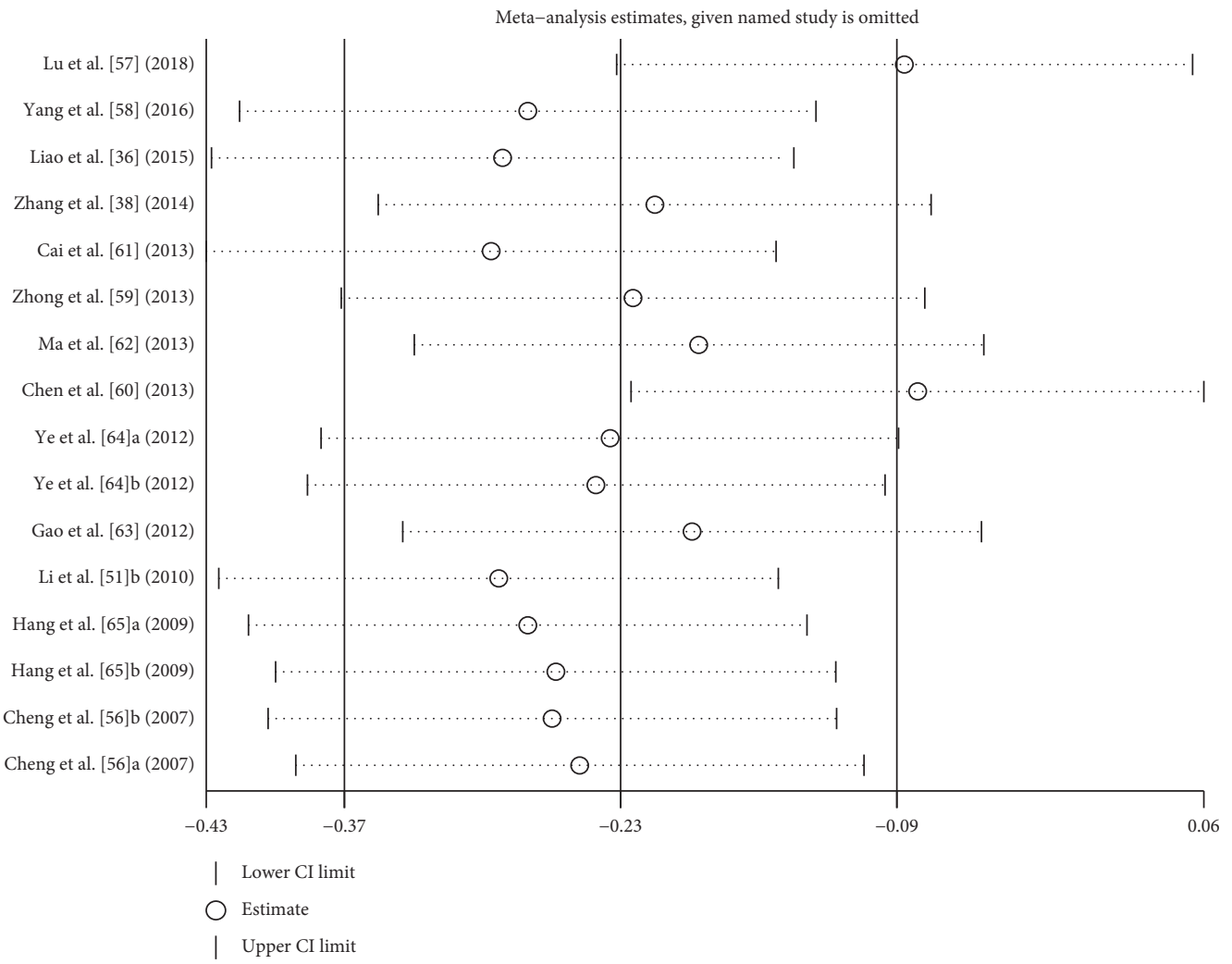

(b)

Figure 5: Sensitivity analysis. (a) Sensitivity analysis of Tregs/PBMCs in AS patients and HCs. (b) Sensitivity analysis of Tregs/CD4 ${ }^{+}$T cells in AS patients and HCs. 
thought to play an important role in the pathogenesis of ankylosing spondylitis [64], but the proportion of Tregs in the PBMC or $\mathrm{CD}^{+} \mathrm{T}$ cells of AS patients has been controversial, and studies have even suggested that Tregs do not participate in the onset of AS [2].

Our overall meta-analysis concluded that the proportion of Treg in AS patients was significantly lower than that in healthy controls, although significant interstudy heterogeneity was evident. We considered that the primary reasons for such unexpected results were due to various inconsistencies, such as the identification of multiple Treg phenotypes using different markers or inconsistencies in the degree of disease activity.

The most likely reason for the dispute in Treg proportions in AS is that Tregs can be classified into different subgroups. Thus, we subanalyzed the Treg data by the markers used for Treg identification, including CD25, FOXP3, and CD127. There are several definitions of Tregs with different cell surface markers, and this seems to be an important source of heterogeneity.

The understanding of Treg cells is still an evolving process, and $\mathrm{CD} 4{ }^{+} \mathrm{CD} 25^{+}$cells were first defined as regulatory T cells in human peripheral blood [65]. Later, FOXP3 proved to be an important marker for regulatory T cells, and it is involved in the establishment and maintenance of Treg cell phenotype $[3,66,67]$. At present, when clinical studies are concerned with the relationship between ankylosing spondylitis and regulatory $\mathrm{T}$ cells, it is recognized that regulatory $\mathrm{T}$ cells mainly include $\mathrm{CD} 4{ }^{+} \mathrm{CD} 25^{+}$, $\mathrm{CD} 4^{+} \mathrm{CD} 25^{\text {high }} \mathrm{FOXP} 3^{+}$, and $\mathrm{CD} 4^{+} \mathrm{CD} 25^{\text {high }} \mathrm{CD} 127^{\text {low }}$ cells $[7,13]$.

Tregs were originally described as expressing the peripheral $\mathrm{CD}^{+}$subpopulation of the $\mathrm{IL}-2$ receptor alpha chain (CD25) [13] and may impair $\mathrm{T}$ cell proliferation by depleting local IL-2 concentrations [8, 68]. Further studies indicate that CD25 is expressed not only on Tregs but also on activated cells lacking regulatory functions, although $\mathrm{CD} 4^{+}$ T cell subsets express the highest levels of CD25 (CD $4^{+}$CD25 high) and exhibit in vitro immunosuppressive properties [15]. Furthermore, it has been reported that CD127 (alpha chain of IL-7 receptor) is upregulated on human T cells after activation and upregulated in Tregs [13], which is inversely correlated with FOXP3 expression levels. Therefore, it has been proposed that staining for CD127 and CD25 can effectively distinguish between Tregs and activated T cells [12]. Classical Treg cells express FOXP3, which is a transcriptional activator of multiple Treg-associated genes [3]. FOXP3, a transcription factor that is expressed at high levels in true Tregs, determines the development and function of Treg cells and is considered to be one of the most specific Treg cell markers [14, 19, 69]. FOXP3 interacts with many other cofactors that are required for the Treg phenotype and function under physiological and pathological conditions $[68,70]$. Tregs in peripheral blood from patients with active AS had lower FOXP3 mean fluorescence intensity than those from healthy controls and could not fully suppress naïve $\mathrm{T}$ cell proliferation [7].

Although studies have confirmed that ASDAS and BASDAI are highly correlated, they are good measures of AS disease activity [71, 72]. But, BASDAI measures disease activity from the patient's perspective, while ASDAS included not only the patient's opinion but also objective measures, such as C Reactive Protein (CRP), and allows measurement of disease activity at any given time point. So, it does not seem justified to substitute one for the other. The proportion of Tregs in patients with active AS patients was significantly less than that in those with inactive AS, suggesting that Treg cell depletion accelerated disease progression. Our result revealed that the different standard chosen to differentiate active AS from inactive AS could also result in heterogeneity.

Although we also conducted a subgroup analysis of the active AS period according to the different criteria of the activity period, the actual disease evaluation scores are different; some may have very high scores, while some may just meet the activity period judgment criteria. In addition, not only in the study of active AS but also in all studies, the disease state of each patient is unlikely to be at the same level, which may be the main source of heterogeneity.

\section{Conclusions}

In conclusion, our meta-analysis also indicates to a certain extent that the absence of Tregs may play an important role in the pathogenesis of AS. This is also consistent with the performance of Tregs in other immune diseases [64]. This will help us further study the pathogenesis of AS, which will help us to treat AS clinically from the perspective of stimulating Treg value.

\section{Conflicts of Interest}

The authors declare that there are no conflicts of interest regarding the publication of this paper.

\section{Acknowledgments}

We would like to show our deepest gratitude to Dr. Zhe Feng, who has provided guidance in every stage of the writing of this thesis. We also would like to thank Editage (https://www.editage.com) for English language editing. This work was supported by the National Natural Science Foundation of China (Grant nos. 81573869 and 81673937).

\section{References}

[1] M. A. Brown, T. Kenna, and B. P. Wordsworth, "Genetics of ankylosing spondylitis-insights into pathogenesis," Nature Reviews Rheumatology, vol. 12, no. 2, pp. 81-91, 2016.

[2] C. Wang, Q. Liao, Y. Hu, and D. Zhong, "T lymphocyte subset imbalances in patients contribute to ankylosing spondylitis," Experimental and Therapeutic Medicine, vol. 9, no. 1, pp. 250-256, 2015.

[3] S. Sakaguchi, M. Miyara, C. M. Costantino, and D. A. Hafler, "FOXP3 $3^{+}$regulatory T cells in the human immune system," Nature Reviews Immunology, vol. 10, no. 7, pp. 490-500, 2010.

[4] A. Y. Rudensky, "Regulatory T cells and FoxP3," Immunological Reviews, vol. 241, no. 1, pp. 260-268, 2011.

[5] P. Sawla, A. Hossain, B. H. Hahn, and R. P. Singh, "Regulatory T cells in systemic lupus erythematosus (SLE); role of peptide 
tolerance," Autoimmunity Reviews, vol. 11, no. 9, pp. 611-614, 2012.

[6] L. T. Madakamutil, I. Maricic, E. Sercarz, and V. Kumar, "Regulatory T cells control autoimmunity in vivo by inducing apoptotic depletion of activated pathogenic lymphocytes," The Journal of Immunology, vol. 170, no. 6, pp. 2985-2992, 2003.

[7] H. Guo, M. Zheng, K. Zhang et al., "Functional defects in $\mathrm{CD}^{+} \mathrm{CD}^{2} 5^{\text {high }}$ FoxP3 $^{+}$regulatory cells in ankylosing spondylitis," Scientific Reports, vol. 6, no. 1, Article ID 37559, 2016.

[8] M. Wang, C. Liu, A. Bond et al., "Dysfunction of regulatory $\mathrm{T}$ cells in patients with ankylosing spondylitis is associated with a loss of Tim-3," International Immunopharmacology, vol. 59, pp. 53-60, 2018.

[9] M. Rosenzwajg, R. Lorenzon, P. Cacoub et al., "Immunological and clinical effects of low-dose interleukin-2 across 11 autoimmune diseases in a single, open clinical trial," Annals of the Rheumatic Diseases, vol. 78, no. 2, pp. 209-217, 2019.

[10] M. Ahmadi, M. Hajialilo, S. Dolati et al., "The effects of nanocurcumin on Treg cell responses and treatment of ankylosing spondylitis patients: a randomized, double-blind, placebo-controlled clinical trial," Journal of Cellular Biochemistry, vol. 121, no. 1, pp. 103-110, 2020.

[11] H. An, X. Li, F. Li et al., "The absolute counts of peripheral T lymphocyte subsets in patient with ankylosing spondylitis and the effect of low-dose interleukin-2," Medicine (Baltimore), vol. 98, no. 15, p. e15094, 2019.

[12] Z. Duan, Y. Gui, C. Li et al., "The immune dysfunction in ankylosing spondylitis patients," BioScience Trends, vol. 11, no. 1, pp. 69-76, 2017.

[13] W. Ji, H. Li, F. Gao, Y. Chen, L. Zhong, and D. Wang, "Effects of Tripterygium glycosides on interleukin-17 and $\mathrm{CD} 4{ }^{+} \mathrm{CD} 25^{+} \mathrm{CD} 127$ low regulatory $\mathrm{T}$-cell expression in the peripheral blood of patients with ankylosing spondylitis," Biomedical Reports, vol. 2, no. 4, pp. 517-520, 2014.

[14] H.-T. Liao, Y.-F. Lin, C.-Y. Tsai, and C.-T. Chou, "Regulatory $\mathrm{T}$ cells in ankylosing spondylitis and the response after adalimumab treatment," Joint Bone Spine, vol. 82, no. 6, pp. 423-427, 2015.

[15] L. Limón-camacho, M. I. Vargas-Rojas, J. Vázquez-mellado et al., "In vivo peripheral blood proinflammatory T cells in patients with ankylosing spondylitis," The Journal of Rheumatology, vol. 39, no. 4, pp. 830-835, 2012.

[16] M. J. Fattahi, H. Ahmadi, F. Jafarnezhad-Ansariha et al., "Oral administration effects of $\beta$-d-mannuronic acid (M2000) on Th17 and regulatory $\mathrm{T}$ cells in patients with ankylosing spondylitis," Biomedicine \& Pharmacotherapy, vol. 100, pp. 495-500, 2018.

[17] M.-H. Chen, W.-S. Chen, H.-T. Lee, C.-Y. Tsai, and C.-T. Chou, "Inverse correlation of programmed death 1 (PD1) expression in $T$ cells to the spinal radiologic changes in Taiwanese patients with ankylosing spondylitis," Clinical Rheumatology, vol. 30, no. 9, pp. 1181-1187, 2011.

[18] S. V. D. Linden, H. A. Valkenburg, and A. Cats, "Evaluation of diagnostic criteria for ankylosing spondylitis," Arthritis \& Rheumatism, vol. 27, no. 4, pp. 361-368, 1984.

[19] H. Yi, Y. Zhen, L. Jiang et al., "The phenotypic characterization of naturally occurring regulatory $\mathrm{CD} 4{ }^{+} \mathrm{CD} 25^{+} \mathrm{T}$ cells," Cellular and Molecular Immunology, vol. 3, no. 3, pp. 189-195, 2006.

[20] C. Zhang, H. Li, X. Liu et al., "Th17 and Treg cells in ankylosing spondylitis Different expression and significance in patients with psoriatic arthritis," Zhongguo Yaowu Yu Linchuang, vol. 19, no. 1, pp. 34-36, 2019.

[21] W. Qing, "Expression of miR-155 in peripheral blood of patients with ankylosing spondylitis and its relationship with Th17/Treg balance," Journal of Shanxi Medical University, vol. 50, no. 2, pp. 235-240, 2019.

[22] C.-1. Wang, K.-z. Li, and W. Cui, "Study on expression of Th1, Th17, Treg cells and related cytokines in ankylosing spondylitis patients," Chronic Pathematology Journal, vol. 19, no. 9, pp. 10-12, 2018.

[23] S. Meng, S. G. Fan, C. Ma et al., "The imbalance of the ratio of TH17 cells to Treg cells on the pathogenesis of ankylosing spondylitis," Chinese Journal of Laboratory Diagnosis, vol. 8, pp. 1364-1365, 2018.

[24] Y. Gou, A Research Related to the Effects of Tumor Necrosis Factor Alpha on the Treatment of Adalimumab and Regulatory $T$ Cells in Active Ankylosing Spondylitis, Shanxi Medical University, Shanxi, China, 2018.

[25] H. An, The Level of $C D 4^{+}$Treg and $C D 8^{+}$Treg Cells in Peripheral Blood of Patient with Ankylosing Spondylitis and the Effect of Low-Dose Interleukin-2, Shanxi Medical University, Shanxi, China, 2018.

[26] Y. Y. Wei, Z. J. Han, H. Y. Huang et al., "Analysis of Treg cells and lymphocyte subgroup in 131 patients with ankylosing spondylitis," China Medical Herald, vol. 14, no. 28, pp. 46-48, 2017.

[27] H. Dong, "Effect of methylprednisolone therapy on T cell subsets and its cytokines of peripheral blood in patients with ankylosing spondylitis," Chinese Journal of Laboratory Diagnosis, vol. 11, no. 21, pp. 1886-1889, 2017.

[28] X. Yang, Changes and Clinical Significance of $C D 8^{+}$Regulatory $T$ Cells Inthe Peripheral Blood of Patients with Ankylosing Spondylitis, Anhui Medical University, Hefei, China, 2017.

[29] M. L. Ren, H. Liu, X. P. Wang et al., "Bone marrow-derived mesenchymal stem cells induced Th17/Treg cell subset imbalance in ankylosing spondylitis," Journal of Spinal Surgery, vol. 14, no. 5, pp. 281-285, 2016.

[30] L. Lei, L. Jian, and L. Jian, "The changes of platelet parameters, TLA and Treg in peripheral blood in patients with ankylosing spondylitis," Zhongguo Linchuang Baojian Zazhi, vol. 19, no. 1, pp. 8-11, 2016.

[31] Y. Zhou, "Comparison of the ratio of TH17 and Treg in patients with ankylosing spondylitis and healthy controls," For All Health, vol. 10, no. 20, pp. 170-171, 2016.

[32] H. Tian, The Influence of Methylprednisolone on Th17/Treg andIL-23/IL-17 in Ankylosing Spondylitis, Shanxi Medical University, Shanxi, China, 2015.

[33] Z. L. Wang, N. F. Zhong, and L. Ma, "The clinical significance of detection of Th1, Th2 and Treg cells in ankylosing spondylitis patients," Journal of Guiyang Medical College, vol. 40, no. 4, pp. 363-367, 2015.

[34] G. H. Xue, L. Hua, X. F. Liu et al., "Frequencies of human regulatory $\mathrm{B}$ cells in $\mathrm{PBMC}$ in ankylosing spondylitis patients and its clinical significance," Chinese Journal of Clinical Laboratory Science, vol. 33, no. 9, pp. 662-667, 2015.

[35] H. L. Zhang, J. Y. Hang, X. Y. Jin et al., "Study on the correlation of the imbalance of Th17 cells, Th1 cell, regulatory T cells with ankylosing spondylitis disease activity score," Medical Recapitulate, vol. 20, no. 24, pp. 4545-4446, 2014.

[36] X. Zhang, P. Wang, Y. F. Wu et al., "Allogeneic blood transfusion alleviates hip joint pain induced by ankylosing spondylitis," Chinese Journal of Tissue Engineering Research, vol. 18, no. 9, pp. 1465-1470, 2014. 
[37] X. J. Li, S. Q. Huang, A. N. Wang et al., "The expression and clinical value of CD40 ligand (CDl54) and $\mathrm{CD} 4{ }^{+} \mathrm{CD} 25^{+} \mathrm{FOXP}_{3}{ }^{+}$regulatory $\mathrm{T}$ cells in patients with ankylosing spondylitis," Zhongguo Jiceng Yiyao, vol. 21, no. 13, pp. 1942-1944, 2014.

[38] X. X. Xu, The Differentiation of Th1/Th17/Treg Cells and Their Expression of Associated Transcription Factors and Cytokines in Patients with Ankylosing Spondylitis, Fujian Medical University, Fuzhou, China, 2013.

[39] J. Han, Expression and Significance of Programmed Death 1 on Peripheral Blood T Cells in Ankylosing Spondylitis Patients, Wenzhou Medical University, Wenzhou, China, 2013.

[40] J. Zhao and Y. Li, "The comparison of the ratio of Th17/Treg cells in patients with ankylosing spondylitis and the normal controls," Chinese Journal of Rheumatology, vol. 17, no. 7, pp. 481-484, 2013.

[41] J. Wang, X. Lin, Y. Wang et al., "Peripheral blood HLA-B27, $\mathrm{T}$ cells and $\mathrm{CD} 5+\mathrm{B}$ cells in the process of ankylosing spondylitis significance," Guide of China Medicine, vol. 11, no. 26, pp. 327-328, 2013.

[42] L. Jian, W. Sihai, W. Lei et al., "Changes of regulatory T cells in peripheral blood in ankylosing spondylitis patients and the influence of Chinese medicine spleen-strengthening unit therapy," Zhongguo Linchuang Baojian Zazhi, vol. 15, no. 1, pp. 1-4, 2012.

[43] C. Q. Zhang, The Role and Significance of Th17 Cells in AS and PsA, Shanxi Medical University, Shanxi, China, 2011.

[44] S.-S. Zhao, J.-W. Hu, J. Wang, X.-J. Lou, and L.-L. Zhou, "Inverse correlation between $\mathrm{CD} 4{ }^{+} \mathrm{CD} 25^{\mathrm{High}} \mathrm{CD} 127^{\text {low/- }}$ regulatory $\mathrm{T}$-cells and serum immunoglobulin $\mathrm{A}$ in patients with new-onset ankylosing spondylitis," Journal of International Medical Research, vol. 39, no. 5, pp. 1968-1974, 2011.

[45] Y. Wu, M. Ren, R. Yang et al., "Reduced immunomodulation potential of bone marrow-derived mesenchymal stem cells induced CCR $4^{+} \mathrm{CCR}^{+}$Th/Treg cell subset imbalance in ankylosing spondylitis," Arthritis Research \& Therapy, vol. 13, no. 1, p. 29, 2011.

[46] X. Li, S. Huang, S. Li et al., "Study the expression of $\mathrm{CD} 4^{+} \mathrm{CD} 25^{\text {high }}$ regulatory T cells in the peripheral blood of AS patients and its correlation with traditional marks," Journal of Medical Research, vol. 39, no. 11, pp. 47-49, 2010.

[47] D. M. Li, X. P. Li, X. M. Li et al., "Frequency of $\mathrm{CD} 4^{+} \mathrm{CD} 25^{+} \mathrm{CD} 127^{\text {low/- }} \mathrm{T}$ cells in the peripheral blood of ankylosing spondylitis patients," Chinese Journal of Allergy \& Clinical Immunology, vol. 2, no. 4, pp. 266-271, 2008.

[48] S. Zhang, Y. Han, J. Wu et al., "The alteration of $\mathrm{CD}^{+}$ regulatory $\mathrm{T}$ cells in patients with Ankylosing Spondylitis Patients," Chinese Journal of Microbiology and Immunology, vol. 28, no. 5, pp. 445-449, 2008.

[49] D. He, F. Cheng, H. Xu et al., "Peripheral blood CD $4^{+} \mathrm{CD} 25^{+}$ regulatory T cells in AS patients," in Proceedings of the $\mathrm{Na}$ tional Symposium on Integrative Ankylosing Spondylitis, Shenzhen City, Guangdong Province, China, 2007.

[50] S. Zhao, X. Li, Z. Zhai et al., "The role of $\mathrm{CD}^{+} \mathrm{CD} 25^{\text {high }}$ regulatory $\mathrm{T}$ ceIls in the pathogenesis of Ankylosing Spondylitis," Chinese Journal of Rheumatology, vol. 11, no. 6, pp. 356-358, 2007.

[51] C. Lu, "The correlation between T cell immune imbalance and disease activity in patients with ankylosing spondylitis," Journal of Clinical Medicine in Practice, vol. 22, no. 3, pp. 128-130, 2018.

[52] F. Yang, X. Zhang, and P. Zhang, "Increased proportion of peripheral blood effector $\mathrm{T}$ cells and decreased programmed
PD protein 1 (PD-L1) levels in patients with active ankylosing spondylitis," Chinese Journal of Cellular and Molecular Immunology, vol. 32, no. 5, pp. 676-679, 2016.

[53] Z. H. Naifeng, Study on Th1/Th2, Th17/Treg in Patients with Ankylosing Spondylitis, Guizhou Medical University, Guiyang, China, 2013.

[54] S. Z. Chen, J. P. Bai, Y. H. Xie et al., "Expression of transcription factor Th17, Treg and Th1 in peripheral blood from patients with ankylosing spondylitis and its correlation with disease activity," Chinese Journal of Immunology, vol. 29, no. 8, pp. 834-838, 2013.

[55] C. Cai and P. Xiao, "Expression of regulatory T cells in the peripheral blood of patients with ankylosing spondylitis," Journal of Chinese Practical Diagnosis and Therapy, vol. 27, no. 12, pp. 1192-1194, 2013.

[56] L. Ma, Y. Zhang, W. Wu et al., "The expression of regulatory $\mathrm{T}$ cells of active ankylosing spondylitis patients related with other indicators," Chinese Journal of Laboratory Diagnosis, vol. 17, no. 11, pp. 1986-1989, 2013.

[57] Y. Gao, Y. Song, Y. Fan et al., "The alteration of Thl7 cells and $\mathrm{CD}^{+} \mathrm{CD} 25^{+} \mathrm{FoxP}^{+}$regulatory $\mathrm{T}$ cells in patients with ankylosing spondylitis," Chinese Journal of Microbiology and Immunology, vol. 32, no. 4, pp. 318-322, 2012.

[58] Q. Ye, Z. Wang, and H. Wu, "Peripheral blood $\mathrm{CD} 4{ }^{+} \mathrm{CD} 25^{\text {high }} \mathrm{CD} 127^{\text {low }}$ Regulatory $\mathrm{T}$ cells in ankylosing spondylitis Meaning," Zhejiang Medicine, vol. 34, no. 2, pp. 143-145, 2012.

[59] H. Huang, Y. Wang, Y. Sun et al., "Expression regulatory T cells in peripheral blood of ankylosing spondylitis patients," China Tropical Medicine, vol. 9, no. 10, pp. 1992-1993, 2009.

[60] F. Cheng, $C D 4^{+} C D 25^{+}$Regulatory T Cells in Peripheral Blood of Patients with Ankylosing Spondylitis, The Second Military Medical University, Shanghai, China, 2007.

[61] D. A. Vignali, "Mechanisms of T(reg) suppression: still a long way to go," Frontiers in Immunology, vol. 3, p. 191, 2012.

[62] E. I. Sega, D. B. Leveson-Gower, M. Florek et al., "Role of lymphocyte activation gene-3 (Lag-3) in conventional and regulatory T cell function in allogeneic transplantation," PLoS One, vol. 9, no. 1, Article ID e86551, 2014.

[63] A. Schmidt, N. Oberle, and P. H. Krammer, "Molecular mechanisms of Treg mediated T cell suppression," Frontiers in Immunology, vol. 3, no. 51, pp. 1-20, 2012.

[64] J. Miao and P. Zhu, "Functional defects of Treg cells: New targets in rheumatic diseases, including ankylosing spondylitis," Current Rheumatology Reports, vol. 20, no. 5, p. 30, 2018.

[65] S. Sakaguchi, "Naturally arising $\mathrm{CD} 4^{+}$regulatory t cells for immunologic self-tolerance and negative control of immune responses," Annual Review of Immunology, vol. 22, no. 1, pp. 531-562, 2004.

[66] N. Komatsu, M. E. Mariotti-Ferrandiz, Y. Wang, B. Malissen, H. Waldmann, and S. Hori, "Heterogeneity of natural Foxp $3^{+}$ $\mathrm{T}$ cells: a committed regulatory T-cell lineage and an uncommitted minor population retaining plasticity," Proceedings of the National Academy of Sciences, vol. 106, no. 6, pp. 1903-1908, 2009.

[67] L. Lu, J. Barbi, and F. Pan, "The regulation of immune tolerance by Foxp3," Nature Reviews Immunology, vol. 17, no. 11, pp. 703-717, 2017.

[68] J. Darce, D. Rudra, L. Li et al., "An N-terminal mutation of the FOXP3 transcription factor Alleviates arthritis but exacerbates diabetes," Immunity, vol. 36, no. 5, pp. 731-741, 2012.

[69] J. Nie, Y. Y. Li, S. G. Zheng, A. Tsun, and B. Li, "FOXP3 ${ }^{+}$Treg cells and gender bias in autoimmune diseases," Frontiers in Immunology, vol. 28, no. 6, p. 493, 2015. 
[70] F. Pan, H. Yu, E. V. Dang et al., "Eos mediates FOXP3-dependent gene silencing in $\mathrm{CD}^{+}{ }^{+}$regulatory T cells," Science, vol. 325, no. 5944, pp. 1142-1146, 2009.

[71] A. Sellas i Fernandez, X. Juanola Roura, A. Alonso Ruiz et al., "Clinical utility of the ASDAS index in comparison with BASDAI in patients with ankylosing spondylitis (Axis Study)," Rheumatology International, vol. 37, no. 11, pp. 1817-1823, 2017.

[72] P. Machado and R. Landewé, "Spondyloarthritis: is it time to replace BASDAI with ASDAS?" Nature Reviews Rheumatology, vol. 9, no. 7, pp. 388-390, 2013. 